\title{
Controlling Gas-Water Interface to Enhance Photocatalytic Degradation of Volatile Organic Compounds
}

Zhenmin $\mathrm{Xu}^{\dagger, \star}$, Wei Chai", Jiazhen $\mathrm{Cao}^{\dagger}$, Fengjiao Huang ${ }^{\dagger}$, Tong Tong ${ }^{\dagger}$, Shuyuan Dong ${ }^{\dagger}$, Qianyu Qiao ${ }^{\dagger}$, Liyi Shi ${ }^{\ddagger}$, Hexing $\mathrm{Li}^{\dagger}$, Xufang Qian ${ }^{\S}$, Zhenfeng Bian ${ }^{\dagger *}$

$\dagger$ The Education Ministry Key Laboratory of Resource Chemistry, Shanghai Key Laboratory of Rare Earth Function Materials, Shanghai Normal University, Shanghai, 200234, China

$\$$ Research Center of Nano Science and Technology, Shanghai University, Shanghai, 200444, China

$\S$ School of Environmental Science and Engineering, Shanghai Jiao Tong University, 800 Dongchuan Road, Shanghai, 200240, China

" Department of Chemical Engineering, Zaozhuang Vocational College, Shandong, 277800, PR. China

*Corresponding author: bianzhenfeng@shnu.edu.cn

\section{Decomposition kinetics model}

The decomposition kinetics was fitted by the first- and second-order reaction models, which are shown as equations (1) and (2), respectively, as follows:

$$
\begin{aligned}
& \ln \left({ }^{C} / C_{0}\right)=-k_{1} t \\
& 1 / C_{t}-1 / C_{0}=k_{2} t
\end{aligned}
$$

Where $t$ is the reaction time; $k_{1}$ is the first-order reaction rate constant $\left(\mathrm{s}^{-1}\right) ; k_{2}$ is the second-order reaction rate constant $\left(\mathrm{ppm}^{-1} \mathrm{~s}^{-1}\right)$; and $C_{0}$ and $C_{t}$ are the initial acetone concentration and the concentration at degradation time $t$ in the reactor, respectively. 

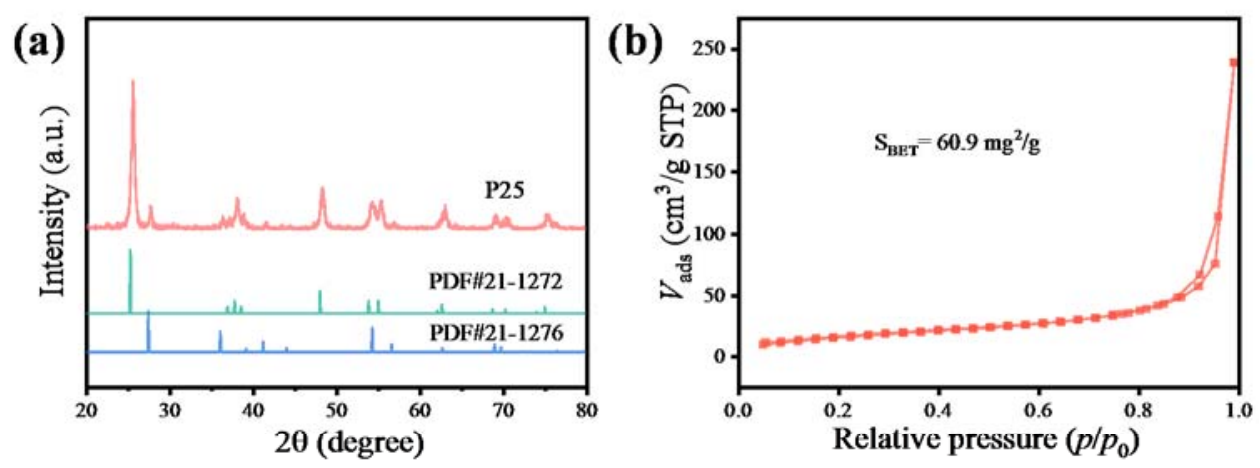

(c)

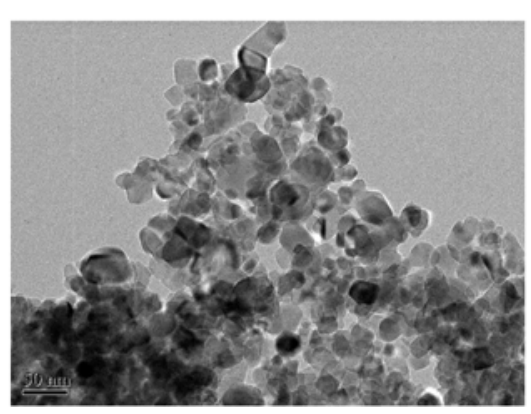

(b)

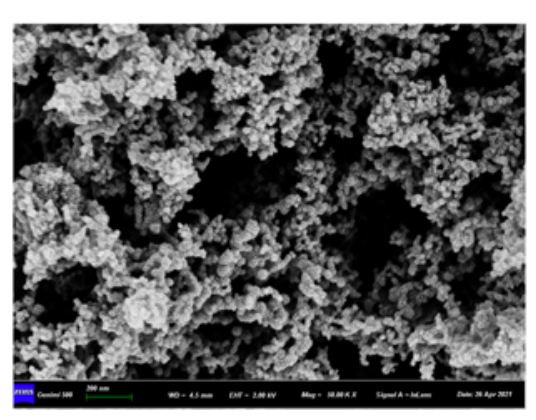

Figure S1 (a) XRD, (b) $\mathrm{N}_{2}$ adsorption-desorption isotherms, (c) TEM and (d) SEM of P25.

P25 possesses a mixed crystal form of anatase and rutile with an average particle size of about $30 \mathrm{~nm}$ and the specific surface area of $60.9 \mathrm{~m}^{2} / \mathrm{g}$.

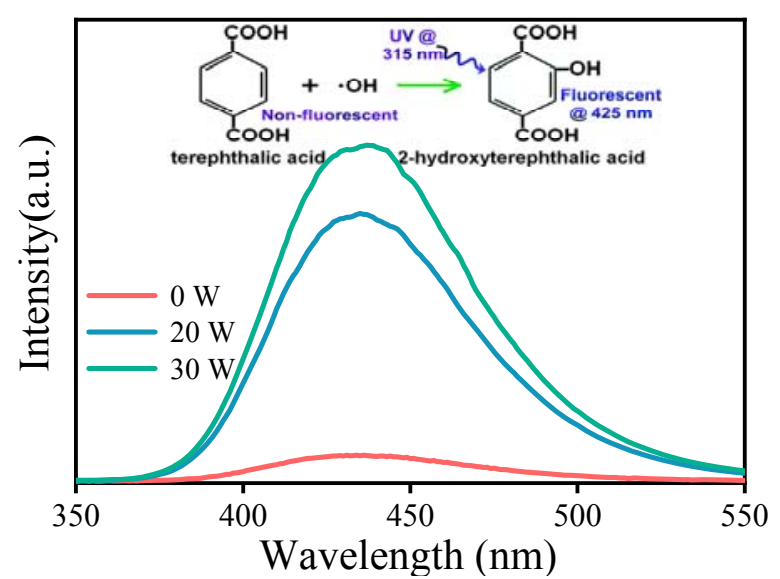

Figure S2 Fluorescence spectra of TAOH solution under excitated at $315 \mathrm{~nm}$ in the APR. 


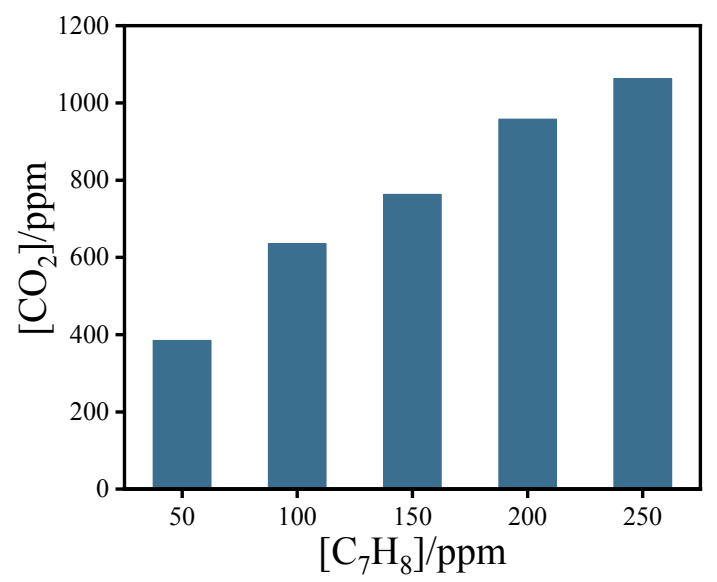

Figure S3 The concentrations of produced $\mathrm{CO}_{2}$ for degradation of toluene with different concentrations in the APR. 

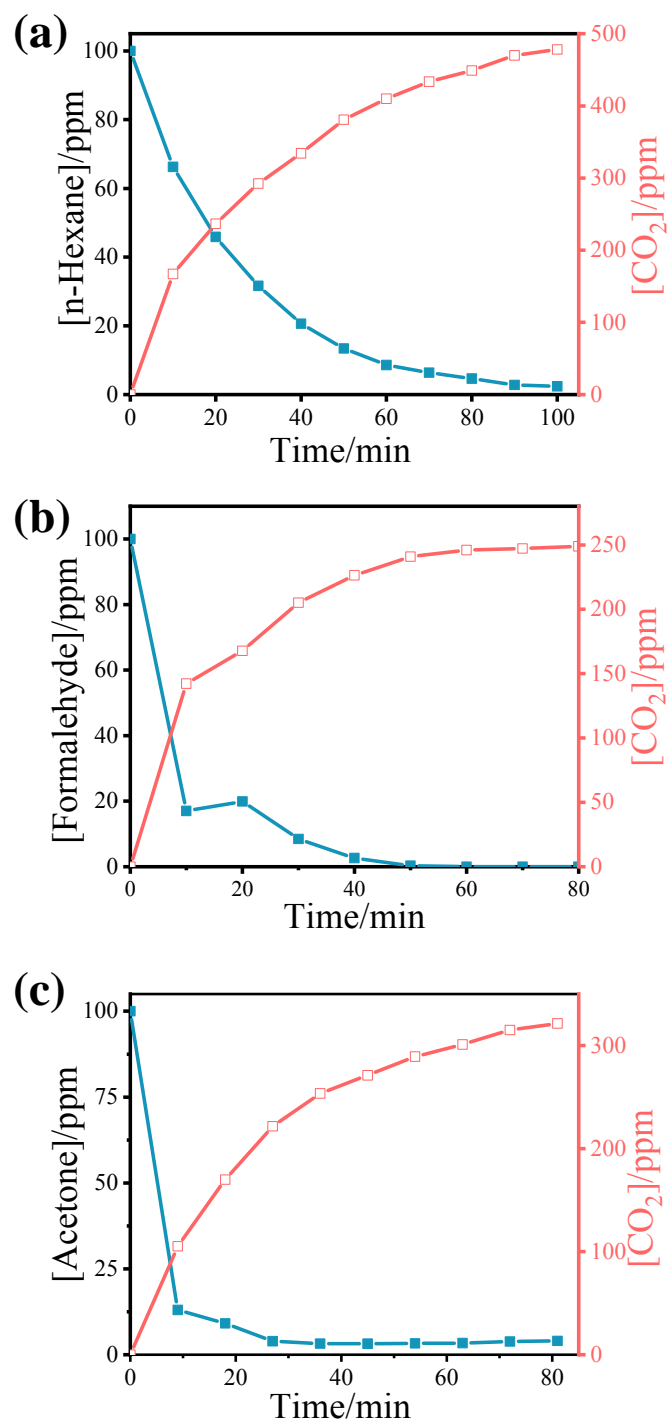

Figure S4 Photocatalytic degradation of (a) n-hexane, (b) formaldehyde, and (c) acetone in the APR. 


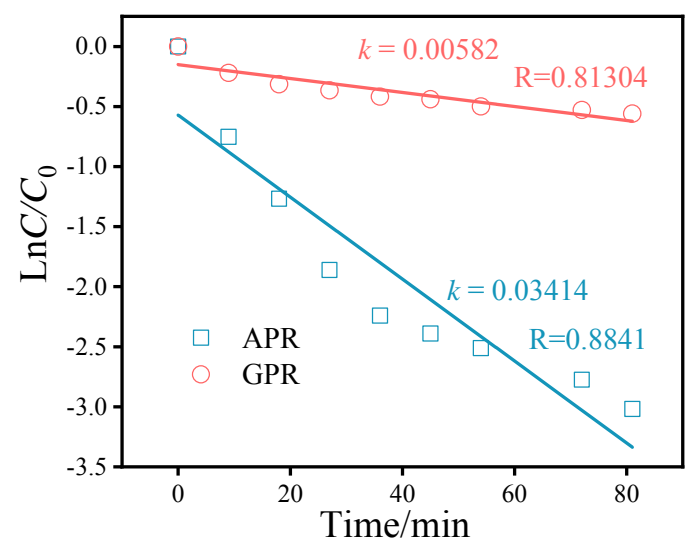

Figure S5 The first-order kinetics curves of Photocatalytic oxidation of toluene in the APR and GPR.
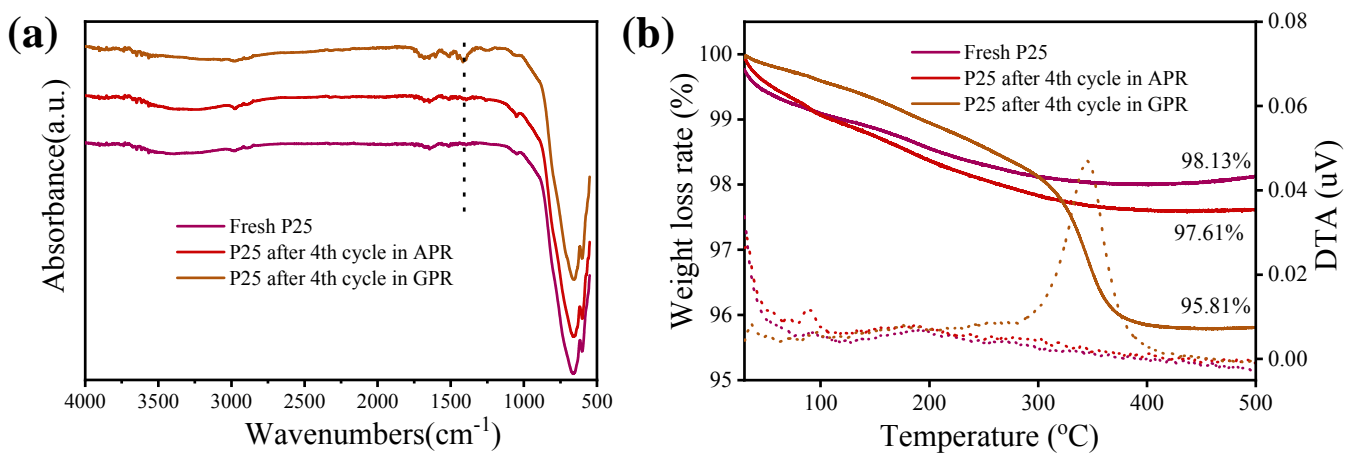

Figure S6 (a) FTIR and (b) TG-DTA of different samples.

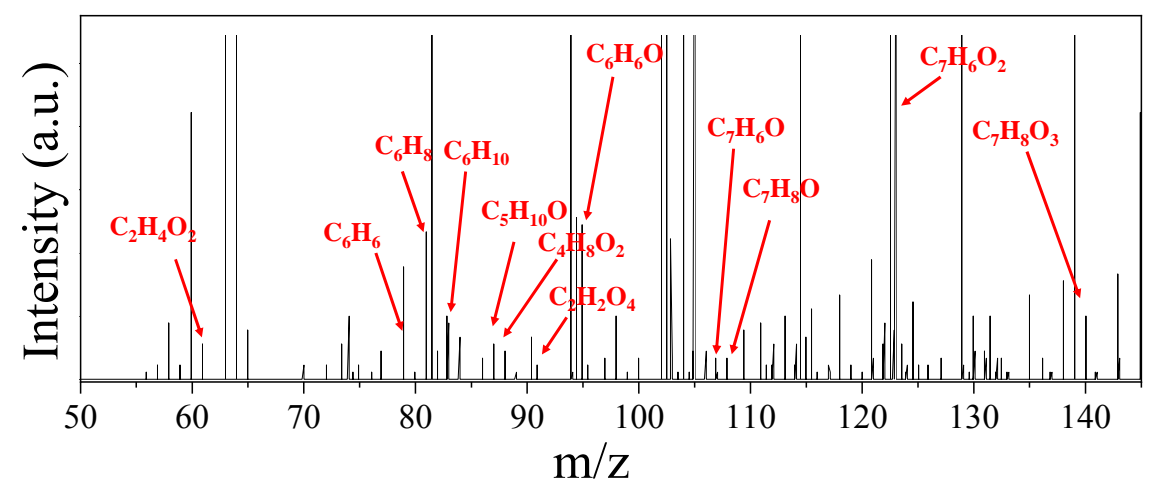

Figure S7 Main identified intermediates of toluene oxidation for $10 \mathrm{~min}$ in the aqueous solution. 


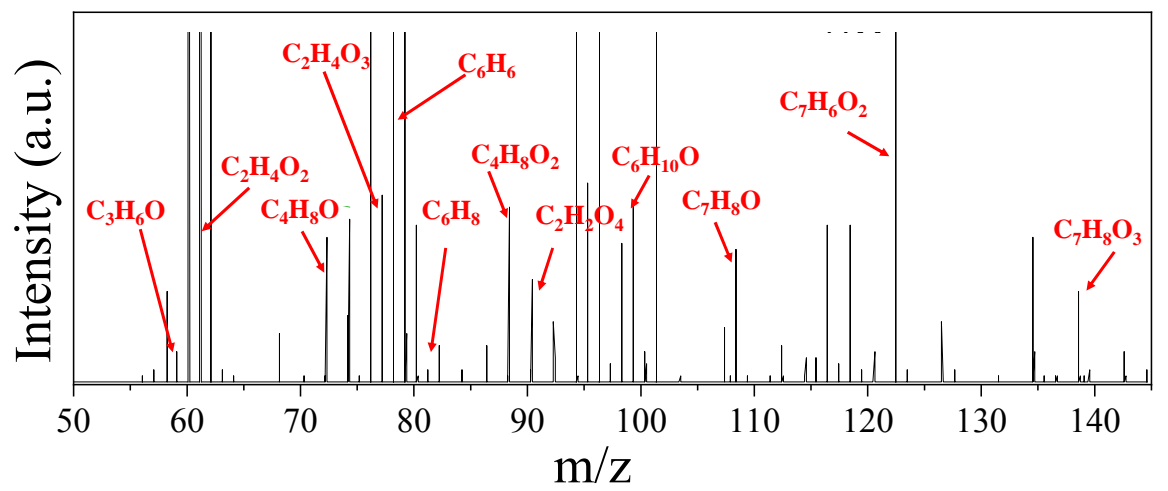

Figure S8 Main identified intermediates of toluene oxidation for $30 \mathrm{~min}$ in the aqueous solution.

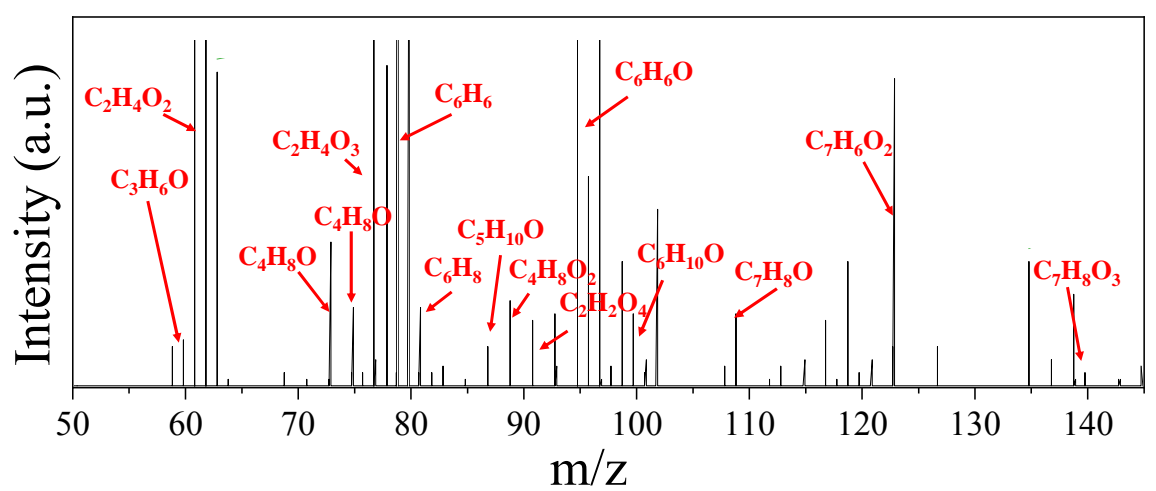

Figure S9 Main identified intermediates of toluene oxidation for $50 \mathrm{~min}$ in the aqueous solution.

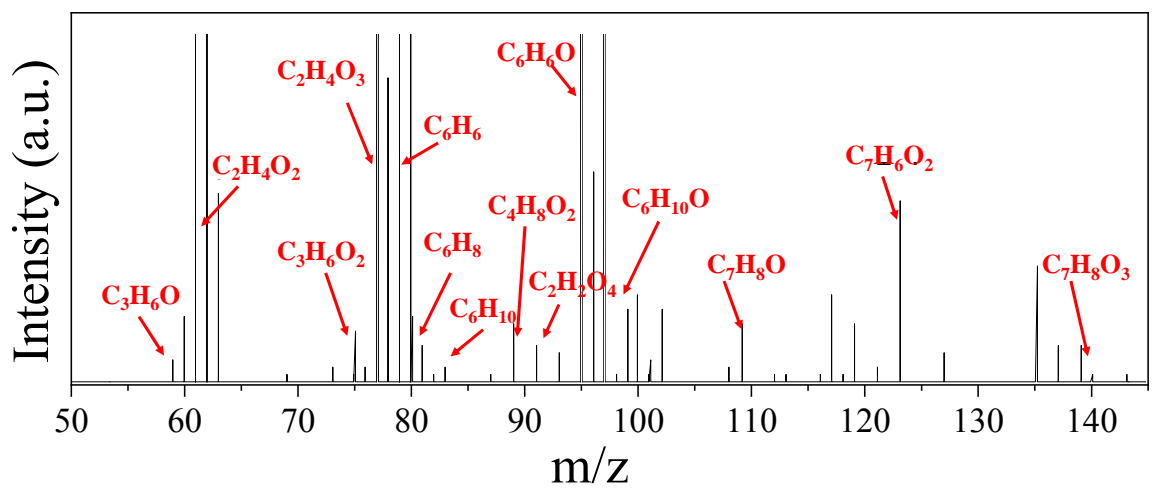

Figure S10 Main identified intermediates of toluene oxidation for70 $\mathrm{min}$ in the aqueous solution. 
Table.S1 The corresponding structure of identified intermediates of toluene oxidation in the APR process.

\begin{tabular}{|c|c|c|c|}
\hline Rank & $\begin{array}{c}\text { Consistent } \\
\text { Formula } \\
\end{array}$ & $\mathbf{m} / \mathbf{z}$ & Corresponding Structure \\
\hline 1 & $\mathrm{C}_{3} \mathrm{H}_{6} \mathrm{O}$ & 59 & \\
\hline 2 & $\mathrm{C}_{2} \mathrm{H}_{4} \mathrm{O}_{2}$ & 61 & \\
\hline 3 & $\mathrm{C}_{4} \mathrm{H}_{8} \mathrm{O}$ & 72 & \\
\hline 4 & $\mathrm{C}_{6} \mathrm{H}_{6}$ & 78 & \\
\hline 5 & $\mathrm{C}_{6} \mathrm{H}_{8}$ & 81 & \\
\hline 6 & $\mathrm{C}_{6} \mathrm{H}_{10}$ & 83 & \\
\hline 7 & $\mathrm{C}_{5} \mathrm{H}_{10} \mathrm{O}$ & 87 & \\
\hline 8 & $\mathrm{C}_{4} \mathrm{H}_{8} \mathrm{O}_{2}$ & 88 & \\
\hline 9 & $\mathrm{C}_{2} \mathrm{H}_{2} \mathrm{O}_{4}$ & 91 & \\
\hline 10 & $\mathrm{C}_{6} \mathrm{H}_{6} \mathrm{O}$ & 95 & \\
\hline 11 & $\mathrm{C}_{7} \mathrm{H}_{6} \mathrm{O}$ & 107 & \\
\hline 12 & $\mathrm{C}_{7} \mathrm{H}_{8} \mathrm{O}$ & 108 & \\
\hline 13 & $\mathrm{C}_{7} \mathrm{H}_{6} \mathrm{O}_{2}$ & 122 & \\
\hline 14 & $\mathrm{C}_{7} \mathrm{H}_{8} \mathrm{O}$ & 124 & \\
\hline 15 & $\mathrm{C}_{7} \mathrm{H}_{8} \mathrm{O}_{3}$ & 140 & \\
\hline
\end{tabular}

